\title{
1 Organic Rankine cycle thermal architecture - from concept to demonstration
}

3 Angad Panesar*, Robert Morgan, Dave Kennaird

4 School of Computing Engineering and Mathematics, University of Brighton, U.K

$5 \quad * a . s . p a n e s a r @ b r i g h t o n . a c . u k$

$7 \quad$ Keywords

8 Internal combustion engine

9 Organic Rankine cycle

10 Working fluid blend

11 Heat recovery arrangement

12 Steady state testing

Highlights

- A versatile heat recovery and working fluid test-rig is presented

- The specific exergy cost consideration supported the direct exhaust gas utilisation

- The water blends offered a noticeable improvement in overall conversion efficiency

- A holistic approach in NOx reduction, downsizing and heat recovery is proposed

- Experimental process parameters corresponded to the near-optimal simulation values

\section{Abstract}

Waste heat to power conversion is expected to play a key role in reducing $\mathrm{CO}_{2}$ emissions in the mid-to-large scale internal combustion engines. The realisation of cost-effective deployment of Organic Rankine Cycles (ORC) is shown to be hindered by several key factors, including, disconnect between parameters considered in simulation studies to those demonstrated experimentally, utilisation of low-grade ORC practice for high-grade applications, challenges in integrating multiple heat recovery sources etc. To address such challenges, a programme of 'concept-to-demonstration' is in progress at the University of Brighton, with the presented focus here being on the thermal architecture. 
31 This paper describes some of the important features of a new experimental ORC test-rig that may

32 contribute towards increased overall conversion efficiencies. These features include, firstly, a

33 variable heat source setup, allowing the potential to replicate a wide range of realistic gaseous

34 sources. Secondly, the direct utilisation of the High-Temperature (HT) exhaust gases, which is

35 expected to lower the specific evaporator exergy cost by $22 \%$. Thirdly, deployment of HT water

36 blends, this is estimated to increase the potential of overall conversion efficiency by 2.4 times.

37 Fourthly, a flexible thermal platform, offering multiple and efficient heat utilisation, with a holistic

38 approach to NOx reduction, downsizing and exhaust heat recovery. Finally, advanced process

39 conditions (e.g. 29.3 bar, $270.9^{\circ} \mathrm{C}$ ), which corresponds to the near-optimal region, and offers the

40 possibility of a $12.5 \%$ conversion rate of heat recovered to expansion power. The potential benefits

41 are quantified using a combination of published literature, procurement findings, simulation results

42 (Aspen HYSYS) and preliminary experimental measurements (NI LabVIEW). The paper concludes

43 with the rational for the next intended research effort, i.e. high-pressure ratio and two-phase

44 expansion machines.

45

\section{Nomenclature}

$\begin{array}{ll}c_{p} & \text { specific heat }\left(\mathrm{kJ} / \mathrm{kg}^{\circ} \mathrm{C}\right) \\ \dot{E} & \text { exergy }(\mathrm{kW}) \\ \text { LMTD } & \text { log mean temperature difference }\left({ }^{\circ} \mathrm{C}\right) \\ \dot{m} & \text { mass flow rate }(\mathrm{kg} / \mathrm{s}) \\ \dot{Q} & \text { energy }(\mathrm{kW}) \\ T & \text { temperature }\left({ }^{\circ} \mathrm{C}\right)\end{array}$

Greek symbols

$\begin{array}{ll}\eta & \text { efficiency } \\ \Delta & \text { difference }\end{array}$

Abbreviations

CAC charge air cooler

EGR exhaust gas recirculation

GWP global warming potential

HEX heat exchanger

$\mathrm{HT}$ high temperature 
exh

out

outlet

$p p$

pinch point (minimum temperature difference between two thermal 60 curves)

\section{Introduction}

Internal Combustion Engines (ICE) are the dominant prime movers for road, marine and rail freight transportation, and decentralised power generation. Due to their high absolute fuel consumption, they represent a significant challenge in terms of $\mathrm{CO}_{2}$ emissions reduction. A key global imperative is therefore the substantial improvement of ICE thermal efficiency. To target the portion of the lost fuel chemical energy, technology road maps and reviews support the specific need for waste heat recovery $[1,2]$. The heat to power conversion technologies are additionally of particular interest to the process industry and the renewable sector $[3,4]$. Heat to power conversion on ICEs has been demonstrated using various methods. However, amongst these, Organic Rankine Cycle (ORC) is

72 stated as one of the preferred technology options when comparing the overall conversion

73 efficiency and its technology readiness level $[5,6]$.

75 Research and development activities have recently become even more relevant due to the

76 automotive sector, where the projected improvements in ICE efficiency are stated to be insufficient

77 to comply with an aggressive $\mathrm{CO}_{2}$ legislation $[7,8]$. The recent developments in key ORC 
components are aiming to address this. Prototypes of fin-tube and spiral-tube evaporators have been demonstrated by Yang et al. and Zhang et al., respectively $[9,10]$. Numerical and experimental results with isentropic efficiencies of $65 \%$ for a two-stage turbine and piston expander have been presented by Seher et al. [11].

The case to implement hydrocarbons and the fourth generation refrigerants is additionally becoming more robust. Using ethanol as the working fluid for a truck application, a fuel consumption improvement of $4.3 \%$ has been shown by Edwards et al. [8]. Due to the increased emphasis on Global Warming Potential (GWP), Yang et al. indicated an ultra-low GWP refrigerant (R1234yf) optimal from a thermo-economic point of view for a marine engine [12].

Application specific heat recovery arrangements for ICEs have also been presented.

Arunachalam et al. theoretically evaluated five different arrangements, even combining Charge Air Cooler (CAC) heat from a truck engine [13]. Due to the considered engine platform, the power produced from Exhaust Gas Recirculation (EGR) only was $72 \%$ compared to the dual-loop arrangement recovering all the three gaseous sources (i.e. exhaust, EGR and CAC). To recover High-Temperature (HT) exhaust and Low-Temperature (LT) coolant heat, Wang et al. proposed a cascade system using R245fa and R134a as the working fluids for the HT and the LT interconnected cycles [14].

Adaptability of ORCs have also led to the proposition of ORCs combined with other technologies. Simulation results by Yilmaz showed that the air conditioning needs of an intercity bus can be realised using the exhaust energy in combination with R134a and R245fa as the working fluids [15]. Shu et al. proposed the use of thermoelectric generator for HT heat recovery, followed by ORC for LT heat recovery in a theoretical study [16].

Despite the advancements, there still exist key challenges hindering the cost-effective deployment of ORCs. Reasons amongst these include, disconnect between parametric values considered in simulation studies to those demonstrated experimentally, utilisation of low-grade ORC practice for high-grade applications, challenges in integrating multiple heat recovery sources in the evolving engine platforms, development of versatile high-pressure ratio expanders (i.e. vapour and two-phase) etc. Extending upon the findings of the recent simulation studies $[17,18]$, this paper 
110 summarises the year-long effort in 'concept-to-demonstration' of a new experimental ORC test-rig.

111 The scope of the work presented here is limited to the important thermal architecture features that

112 may contribute towards investigating increased overall conversion efficiencies. The paper consists

113 of two main sections, the methodology phase and the demonstration phase, which utilise a

114 combination of published literature, procurement findings, simulation results (Aspen HYSYS V8

115 [19]) and preliminary experimental measurements (NI LabVIEW 2014 [20]). In the methodology

116 section, focus is given to the rationale behind the heat source setup, utilisation of exhaust gases,

117 the chosen working fluids, process operating conditions and the flexible thermal platform. In the

118 demonstration section, the current capability of the experimental ORC test-rig and the preliminary

119 thermal platform results are presented and discussed. Finally, the paper concludes with the

120 intended research efforts with expansion machines.

1222 Methodology phase

\section{$123 \quad 2.1$ Heat source setup}

124 Figure 1a presents the range of heat quality and the proportion of fuel chemical energy wasted by 125 typical mid-to-large scale ICE (0.2-2 MW) utilising a range of fuels (e.g. bio-diesel, natural gas) and 126 regulated emissions standards (e.g. Euro 6, Tier III). In freight transportation, such engines operate 127 at near-steady state conditions, typically between the mid-speed mid-load point and the engine 128 rated condition. Heat recovery from the post-turbine exhaust remains a primary choice across 129 various engine platforms. Figure 1a also includes the EGR stream, which is a potential secondary 130 choice for heat source. Additionally, the continued trend of cooler engine intake temperatures and 131 higher engine intake pressures now means that, from an exergy perspective, the CAC is also a 132 potential secondary choice in engines operated at relatively high speeds and loads. Figure 1a then 133 illustrates that a suitable heat source setup for testing ORCs must offer a wide range of gaseous 134 heat quality and quantity levels. 

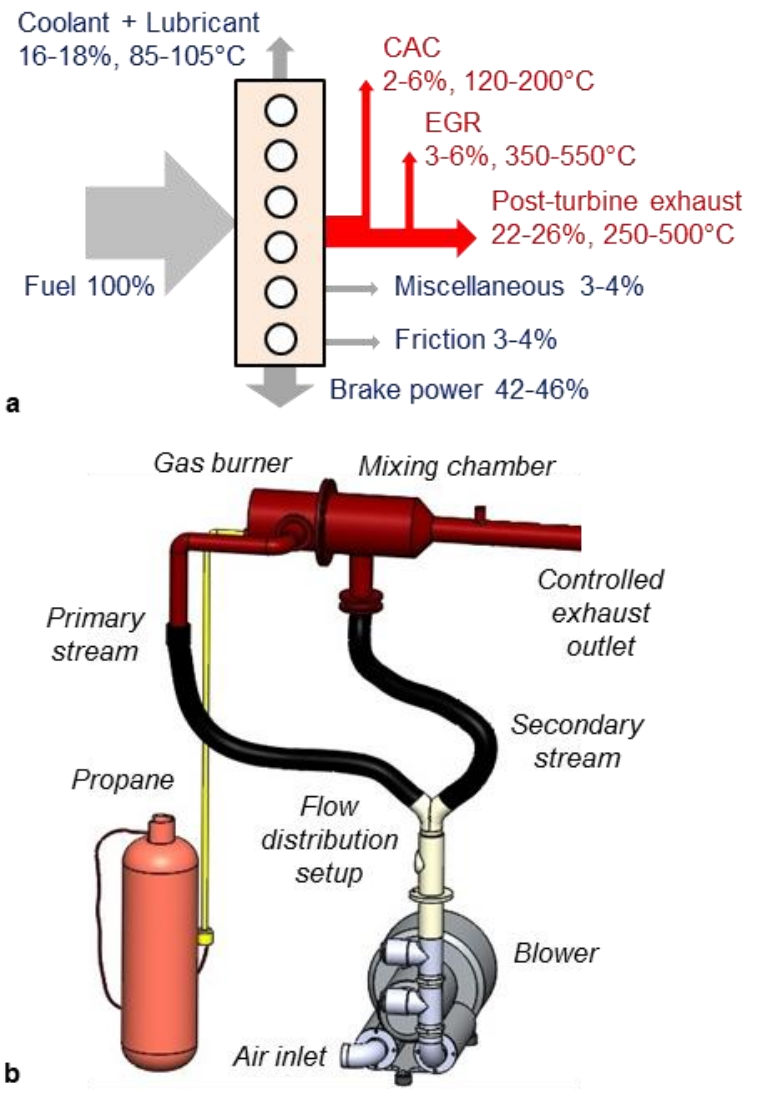

137 Figure 1 (a) Fuel chemical energy distribution with various regulated emissions standards in a range of mid-to-large scale ICEs at mid-to-high speeds and loads (b) Test-rig section representation of the variable heat source setup

141 To offer this flexibility, while avoiding the challenge of integrating and operating engine test-beds in parallel, the waste heat was experimentally simulated using a blower (Elmo Rietschle $2 \mathrm{BH} 1$ side channel, $0.35 \mathrm{~kg} / \mathrm{s}$ ) and gas burner (Maxon 3" TUBE-O-THERM, $120 \mathrm{~kW}$ ) combination, as shown by the test-rig section representation in Fig. 1b. The compressed air flow exiting the blower was distributed into two streams, the primary compressed air stream acted as the main air supply to the gas burner, the secondary compressed air stream was used for dilution purposes. This was since, firstly, the burner exhaust gas temperature is typically well above the maximum engine exhaust gas target temperature of $500^{\circ} \mathrm{C}$. By utilising the secondary compressed air stream and controlling the quantity of flow using the flow distribution setup (which includes 2 butterfly valves), the net exhaust gas temperature can be controlled. Secondly, the gas burner must be accompanied with a higher pressure air stream since, ambient gas burners either cannot operate when faced with the 152 backpressures that will be introduced by the exhaust heat exchanger (HEX), or produce emissions higher than those required to certify their operational use. As a result, depending on the fuel supply 
154 to the gas burner, quantities of primary and secondary compressed air flows, and the backpressure 155 created by the HEX, this flexible heat source setup has the potential to deliver gaseous heat 156 qualities between $200-500^{\circ} \mathrm{C}$ and heat quantities between $12-120 \mathrm{~kW}$, at a pressure of $157 \quad 1.05-1.25$ bar.

\section{$159 \quad 2.2$ Utilisation of exhaust gases}

160 To recover the relatively HT exhaust gas heat of ICEs, the approach of using an intermediate 161 thermal-oil loop is often proposed and implemented. As shown in Fig. 2a, the diathermic-oil 162 recovers the $\mathrm{HT}$ exhaust gas heat, and transfers it to the ORC working fluid. A similar process 163 integration was also proposed by Shu et al. for automotive heat recovery using conventional 164 refrigerants like R245fa and isopentane [21].

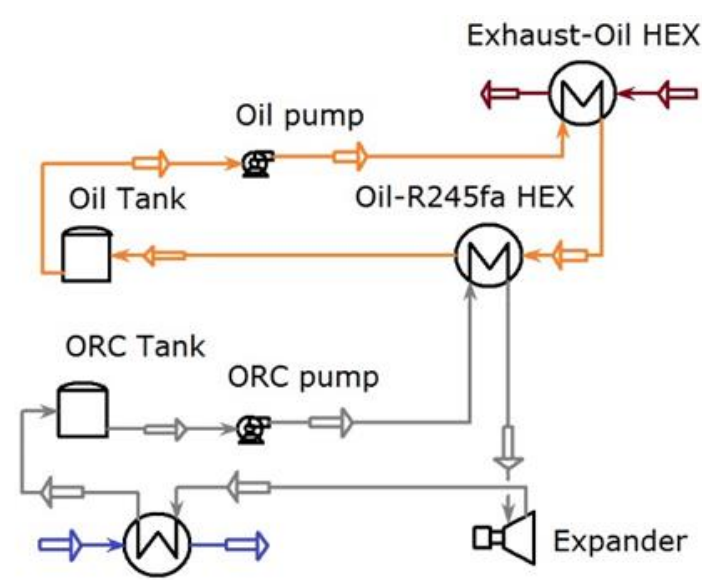

a Condenser

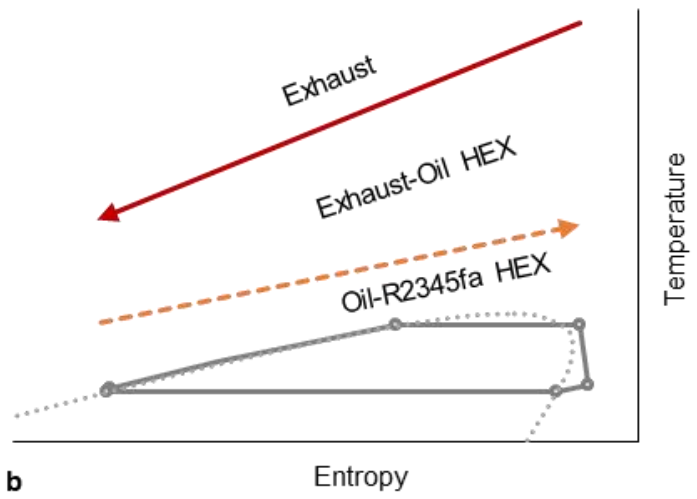

167 Figure 2 Thermal-oil loop coupled with a conventional LT ORC (a) System schematic (b) T-S sketch 168

Due to the reduced heat source temperature entering the ORC, the thermal-oil loop approach has two key advantages. Firstly, a reduced risk of thermal degradation in the organic fluid, and 
171 secondly, utilisation of conventional refrigerants and off-the-shelf components for the ORC. If the

172 pressure and temperature limits of the ORC do not change with the addition of the thermal-oil

173 loop, and the maximum available waste heat is transferred to the thermal-oil, then the system

174 power of the ORC will not reduce noticeably. This is since, the total heat transfer losses in the heat

175 recovery process are divided between the two separate HEXs, as illustrated in the

176 temperature-entropy sketch in Fig. 2b.

177

178 Unfortunately, the thermal-oil loop approach also introduces a number of disadvantages. The

179 additional sub-system components include the exhaust-oil HEX, the oil tank and the oil pump.

180 Therefore, for roughly equal net power, the system complexity, size, weight and failure points may

181 potentially increase. Furthermore, published literature focused on development activities has

182 indicated that the specific cost of a LT ORC coupled with a thermal-oil loop is expected to be $15 \%$

183 higher when compared to HT exhaust gases being recovered directly in a HT ORC [22].

Operational capability and purchase cost data of numerous HT and LT evaporators in the range of 38-80 kW was compiled during the decision and procurement phase. Table 1 summarises the data for evaporator duty scaled to $50 \mathrm{~kW}$ (using $\mathrm{f} / \mathrm{kW}$ ), where Case 1 and 2 represents the LT and the HT ORC approaches, respectively. The comparison was done for an equal quality and quantity of exhaust heat recovered in both cases. When considering the specific energy cost for the ORC evaporator, the HT ORC results in a value 2.8 times higher (42 vs. $116 \mathrm{f} / \mathrm{kW}$ ). However, such parameters ignore the heat quality available to the working fluid and the additional oil-loop costs, 


\begin{tabular}{|c|c|c|}
\hline & Case1 & Case 2 \\
\hline & \multicolumn{2}{|c|}{$\begin{array}{l}\text { Thermal oil HT } \\
+ \text { LT ORC ORC }\end{array}$} \\
\hline Max. oil temp. in ORC evap. (K) & 498 & - \\
\hline Min. oil temp. in ORC evap. (K) & 393 & - \\
\hline Avg. oil temp. in ORC evap. (K) & 443 & - \\
\hline Max. exhaust temp. in ORC evap. (K) & - & 673 \\
\hline Min. exhaust temp. in ORC evap. (K) & - & 393 \\
\hline Avg. exhaust temp. in ORC evap. (K) & - & 521 \\
\hline Cost of the thermal-oil loop system $(£)$ & 2350 & - \\
\hline Cost of the ORC evap. (£) & 2100 & 5800 \\
\hline Specific energy cost of the ORC evap. (£/kW) & 42 & 116 \\
\hline Exergy of the heat source in the ORC evap. (kW) & 9.1 & 15.1 \\
\hline Specific exergy cost of the ORC evap. (£/kW) & 231.6 & 383.3 \\
\hline $\begin{array}{l}\text { Specific exergy cost of the ORC evap. including } \\
\text { thermal-oil loop cost }(£ / \mathrm{kW})\end{array}$ & 490.7 & 383.3 \\
\hline $\begin{array}{l}\text { Courtesy of, HTT energy GmbH, ICS Cool Energy } \\
\text { Wanson UK Ltd., Beverley Environmental Ltd., SI } \\
\text { Group Co., FUNKE GmbH, Graham Corporation, } \\
\text { International AB, Vahterus UK Ltd., Baode Heat } \\
\text { Danfoss Ltd., and Dover Intercompany Services } ~\end{array}$ & $\begin{array}{l}\text { Fulton Ltd., } \\
\text { inghai Acces } \\
\text { ylem Inc., Tr } \\
\text { changer Co. } \\
\text { K Ltd. }\end{array}$ & $\begin{array}{l}\text { Babcock } \\
\text { ssen } \\
\text { ranter } \\
\text {, }\end{array}$ \\
\hline
\end{tabular}

As a result, the specific exergy cost for the ORC evaporator (including the thermal-oil loop cost) was considered. The recoverable exergy $\left(\dot{E}_{\text {recover }}\right)$ of the heat in the evaporator $\left(\dot{Q}_{\text {evap }}\right)$ was calculated using the exhaust average temperature ( $\left.T_{\text {exh avg }}\right)$.

$\dot{E}_{\text {recover }}=\dot{Q}_{\text {evap }}\left[1-\left(T_{\text {radiator }} / T_{\text {exh avg }}\right)\right]$

210 Where, $T_{\text {exh avg }}=\left(T_{\max }-T_{\min }\right) / \ln \left(T_{\max } / T_{\min }\right)$. Furthermore, $\dot{E}_{\text {recover }}$ utilises $T_{\text {radiator }}\left(90^{\circ} \mathrm{C}\right)$ rather than $211 T_{a m b}\left(20^{\circ} \mathrm{C}\right)$, since this represents the thermal limit when considering a realistic engine cooling module. Similarly, the considered $T_{\max }\left(400^{\circ} \mathrm{C}\right)$ represents the design point limit, rather than the

213 higher engine rated condition $\left(500^{\circ} \mathrm{C}\right)$. Despite the higher ORC evaporator cost ( $f 5800$ vs. $\left.f 2100\right)$

214 for the HT ORC approach, the higher exergy available in the ORC evaporator (15.1 kW vs. 9.1 kW) and no additional thermal-oil loop cost ( $£ 0$ vs. $£ 2350$ ) resulted in a $22 \%$ lower specific exergy cost for the ORC evaporator (490.7 vs. $383.3 \mathrm{f} / \mathrm{kW}$ ).

In addition to the above economic approach, the choice of direct exhaust heat recovery is also supported by the thermodynamic approach. This is since, the thermal-oil loop fails to provide opportunity to reduce the overall system irreversibility. Fundamentally, such systems cannot take full advantage of the HT heat, and mimic LT heat recovery systems. Hence, efforts were focused in 
engaging the process industry supply chain in co-designing a HEX for direct exhaust gas and working

223 fluid use.

As a result, a multi-pass welded shell-and-plate HEX, with a heat transfer area and liquid volume of $11.9 \mathrm{~m}^{2}$ and $0.0126 \mathrm{~m}^{3}$, was procured from Vahterus UK. The design point parameters include: low

227 fluid and exhaust side pressure drop of 0.19 bar and 0.03 bar; capability to operate under high temperature $\left(380^{\circ} \mathrm{C}\right)$ and pressure $(40 \mathrm{bar})$; and average working fluid temperature of $210^{\circ} \mathrm{C}$ and Log Mean Temperature Difference (LMTD) of $58^{\circ} \mathrm{C}$. This HEX is suitable for superheating hydrocarbons and water-hydrocarbon blends.

\subsection{Working fluid}

233 Waste heat recovery below $200^{\circ} \mathrm{C}$ can be considered relatively mature using ORCs with hydrofluorocarbons like R245fa $[1,4]$. As a result, these fluids have also been suggested for HT exhaust gas heat recovery, either directly or with a thermal-oil loop. However, they result in lower overall conversion efficiencies due to the lower work potential. To investigate and address this issue, a two-part simulation study was undertaken, firstly to identify suitable working fluids, and secondly to propose a flexible thermal platform.

Recent simulation studies have shown that, alcohols and water-alcohol blends that are not included in widely used fluid data bases like REFPROP 9 can provide an improved case for $250-450^{\circ} \mathrm{C}$ heat recovery [17]. Amongst the numerous blends, water-propanol blend with water mass fraction between $25-50 \%$ can offer a suitable trade-off in view of thermodynamic, thermophysical, chemical, environmental, safety, cost, availability, compatibility, miscibility and decomposition Utilising the parameters, boundary conditions and assumptions presented in Table 2 (column 1 and 2), which are representative of a truck exhaust heat recovery, Fig. 3 presents the potential of net ORC power against the primary process and sizing parameters for R245fa and water-propanol blend (50/50 by mass). The two process parameters include, firstly, maximum fluid temperature, and secondly, maximum fluid pressure. The two sizing parameters include, firstly, the product of heat transfer coefficient and area per unit of net ORC power (i.e. UA/kW net), and secondly, expansion 
253 volume flow ratio per unit of net ORC power (i.e. VFR/kW net). The utilised ORC energy modelling

254 equations have extensively been published and their repetition is avoided [23-26].

256 Table 2 Parameters, boundary conditions and assumptions representative of long-haul Euro 6 truck 257 waste heat recovery

\begin{tabular}{|c|c|c|c|}
\hline Parameters & Values & Parame & Values \\
\hline \multicolumn{2}{|c|}{ (For Fig. 3 and Table 3) } & \multicolumn{2}{|c|}{ (Additional for Table 3) } \\
\hline$\overline{T_{e x h}}$ & $400^{\circ} \mathrm{C}$ & $T_{E G R}$ & $500^{\circ} \mathrm{C}$ \\
\hline$\dot{m}_{e x h}$ & $0.2 \mathrm{~kg} / \mathrm{s}$ & $\dot{m}_{E G R}$ & $0.03 \mathrm{~kg} / \mathrm{s}$ \\
\hline$c_{p e x h}$ & $1.15 \mathrm{~kJ} / \mathrm{kg}^{\circ} \mathrm{C}$ & $c_{p E G R}$ & $1.15 \mathrm{~kJ} / \mathrm{kg}^{\circ} \mathrm{C}$ \\
\hline$T_{\text {cooling air }}$ & $35^{\circ} \mathrm{C}$ inlet, $55^{\circ} \mathrm{C}$ exit & $T_{p p E G R}$ & $30^{\circ} \mathrm{C}$ \\
\hline$T_{p p e x h}$ & $30^{\circ} \mathrm{C}$ & $T_{C A C}$ & $140^{\circ} \mathrm{C}$ \\
\hline$T_{\text {condensing }}$ & $90^{\circ} \mathrm{C}$ & $\dot{m}_{C A C}$ & $0.19 \mathrm{~kg} / \mathrm{s}$ \\
\hline$T_{\text {sub-cooling }}$ & $5^{\circ} \mathrm{C}$ & $c_{p E G R}$ & $1.01 \mathrm{~kJ} / \mathrm{kg}^{\circ} \mathrm{C}$ \\
\hline$T_{\text {superheat }}$ & $5^{\circ} \mathrm{C}$ & $T_{p p C A C}$ & $10^{\circ} \mathrm{C}$ \\
\hline$\eta_{\text {pump }}$ & $50 \%$ & $T_{p p I H E}$ & $10^{\circ} \mathrm{C}$ \\
\hline$\eta_{\text {expander }}$ & $65 \%$ & & \\
\hline \multicolumn{4}{|c|}{$\Delta P_{\text {fluid side all HEXs }} 0.1 \mathrm{bar}$} \\
\hline
\end{tabular}

259
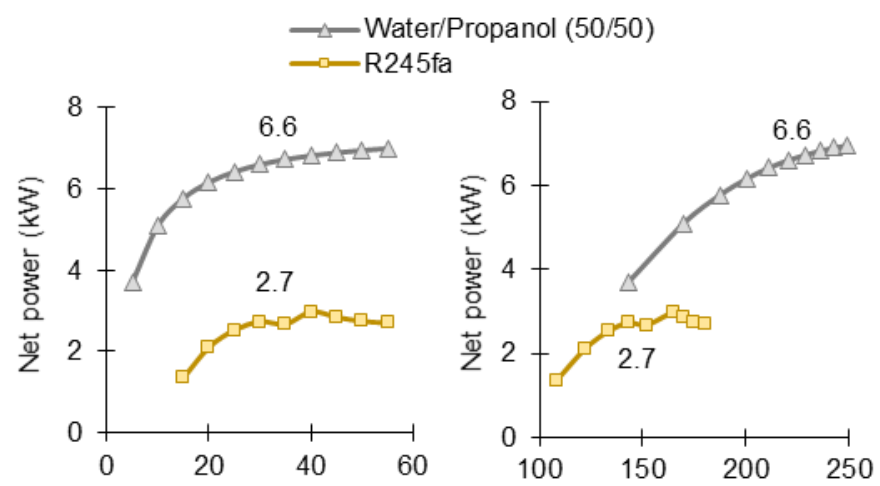

a Max. fluid pressure (bar)

b Max. fluid temperature $\left({ }^{\circ} \mathrm{C}\right)$
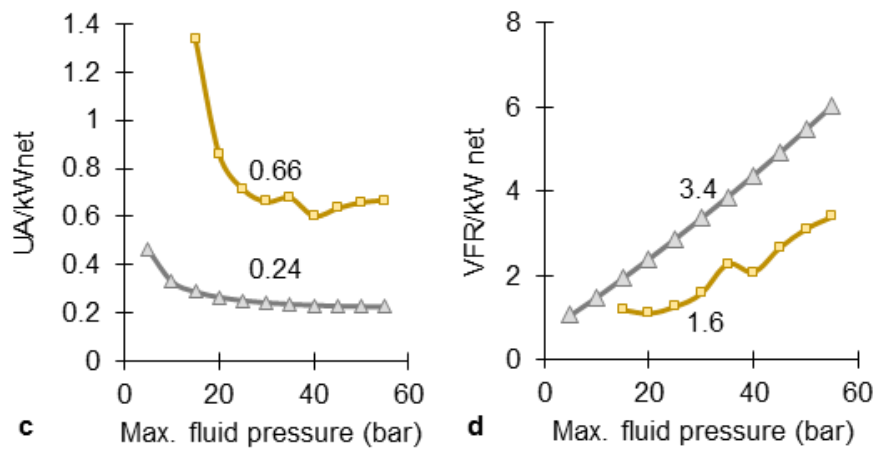

Figure 3 Performance potential comparison between R245fa and water-propanol (50/50). 
Considering the subcritical R245fa operation (Fig. 3a), the 30 bar value was considered near-optimal, offering $2.7 \mathrm{~kW}$ of net power for $57 \mathrm{~kW}$ of heat recovery $\left(\eta_{\text {thermal }}=4.7 \%\right)$. At the same maximum cycle pressure, the water-propanol blend offered 2.4 times higher net power for a reduced $48 \mathrm{~kW}$ of heat recovery $\left(\eta_{\text {thermal }}=13.8 \%\right.$ ). However, compared to R245fa (Fig. 3b), which required a maximum temperature of around $145^{\circ} \mathrm{C}$, the water-propanol blend required a much higher value of $225^{\circ} \mathrm{C}$. Both the above primary process parameter results are linked to the relatively higher normal boiling point of the water-propanol blend compared to $\mathrm{R} 245 \mathrm{fa}\left(89^{\circ} \mathrm{C}\right.$ vs. $\left.15^{\circ} \mathrm{C}\right)$. When the near-optimal operation of pure propanol and water-propanol blend (50/50) was considered, the temperature/pressure limit of $240^{\circ} \mathrm{C} / 25$ bar and $245^{\circ} \mathrm{C} / 35$ bar was established, respectively. The maximum temperature limit was based on a $20^{\circ} \mathrm{C}$ superheat, such higher superheating margins are essential in transient conditions when using conventional expansion machines.

As a first indicator for the relative heat transfer footprint (Fig. 3c) and expansion machine size (Fig. 3d), UA/kW net and VFR/ $/ W_{\text {net }}$ were considered $[27,28]$. With the reduction in the heat transfer footprint being a prime consideration, the water-propanol blend showed a potential of $60 \%$ reduction in the overall heat transfer footprint (Fig. 3c). The above parameters then guided the co-design and procurement stage of the desired HT HEX described in the section 2.2. Note that, although Fig. 3d indicates a relative expansion machine size requirement for water-propanol blend being 2.1 times that of R245fa, nonetheless, the absolute VFR requirement was within the reach of piston expanders. Hence, the above results aided the continued examination of water-propanol blend as an alternative. Pure water was not considered for comparison due to its large latent heat and freezing point drawbacks in the current application.

\subsection{Thermal architecture}

The thermal architecture of ORCs are expected to differ amongst the variety of ICE applications [1, 5]. Hence, a flexible thermal platform with the potential to be modified for either multiple heat recovery and/or efficient heat utilisation is essential for research activities. Figure 4a presents the HYSYS model section of the proposed thermal platform. The red and grey coloured streams correspond to external heat and working fluid, respectively. The heat recovery platform comprises of two LT HEXs in a parallel branched flow followed by one HT HEX. Figure $4 b$ represents the corresponding test-rig section. 


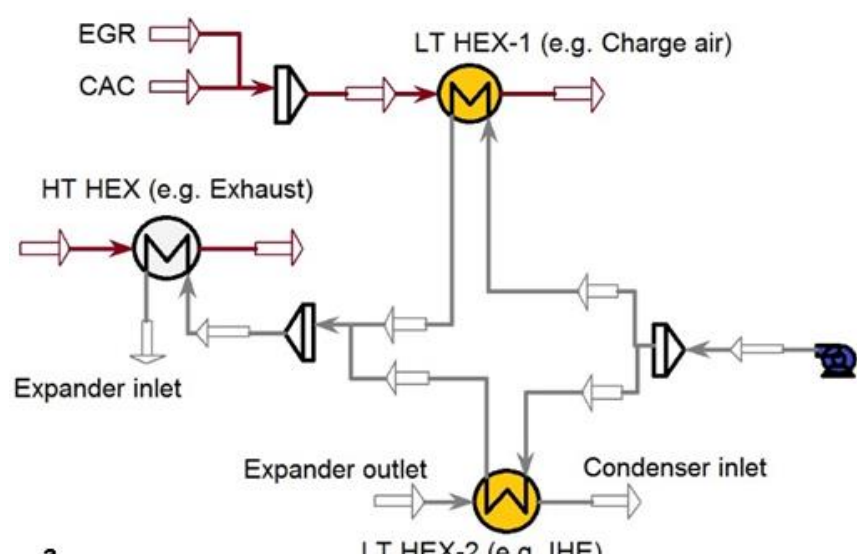

a

LT HEX-2 (e.g. IHE)

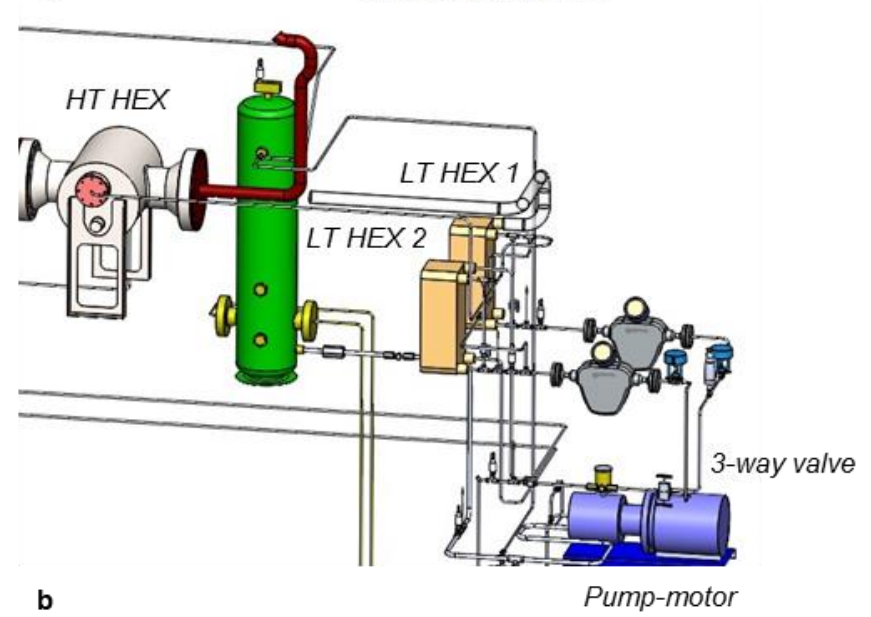

Figure 4 Proposed heat recovery platform with two HEXs in a parallel flow followed by one HEX in series flow (a) HYSYS model (b) Test-rig representation

Using pure propanol as the working fluid, Table 3 summarises the results for comparing the possible heat recovery options. The parameters are normalised to the net heat recovered in the exhaust heat recovery only option. Furthermore, the heat recovery options were targeted for the same net power and with an equal maximum pressure of 25 bar, as stated in section 2.3. For this case study, the earlier used truck exhaust heat recovery parameters (Table 2, column 1 and 2), together with the EGR and CAC parameters (i.e. column 3 and 4 ) were utilised. 


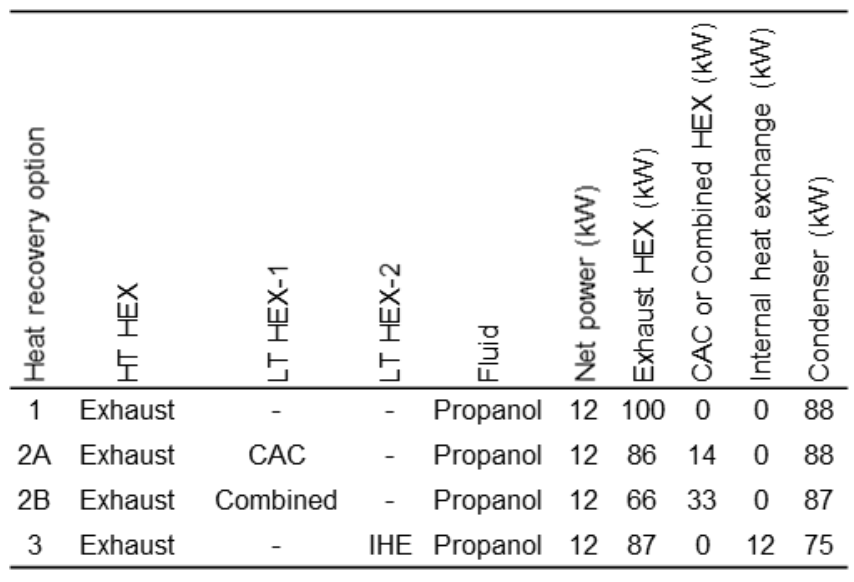

317 Option 1 from Table 3, i.e. exhaust gas heat recovery only, can be considered as a potential solution 318 where EGR and charge air heat is expected to be minimal. Option 2, i.e. exhaust gas and lower 319 temperature heat recovery, can be deployed in two different cases. Case 2A being where exhaust 320 and charge air heat is recovered in series. Case 2B being where both charge air and EGR heat is 321 mixed and recovered in a combined larger LT HEX located post-compressor followed by exhaust 322 heat in series.

324 The Ricardo WAVE 2015 [29] model section of the baseline 6-cylinder engine utilised for Case 1 325 and $2 \mathrm{a}$ is presented in Fig. 5a. For brevity, excluded is the after-treatment system, which is used in 326 conjunction with the EGR to meet Euro 6 emissions. The modified engine platform (Fig. 5b) was 327 simulated under the same recirculation rate (15\%), engine intake pressure (2.5 bar), temperature $328\left(65^{\circ} \mathrm{C}\right)$ and fuelling parameters to that of the baseline platform (Fig. 5a). Hence, the regulated 329 emissions are expected to be similar. 

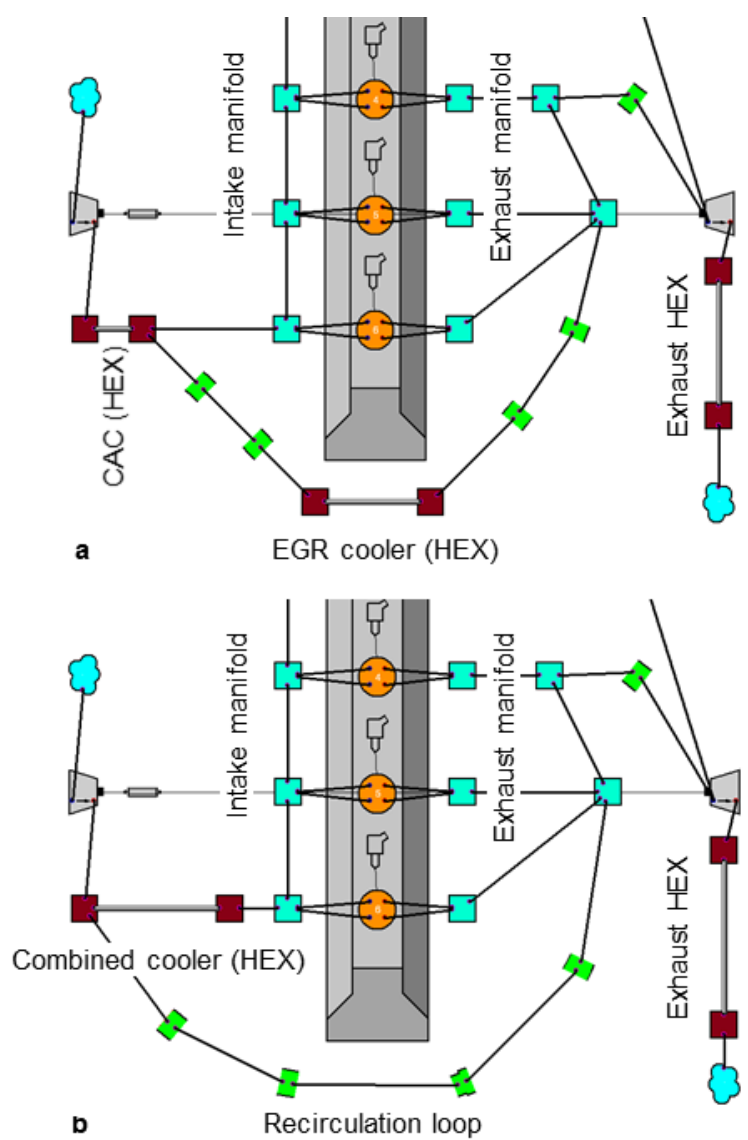

Figure 5 Ricardo WAVE model section of the truck engine platform (a) Typical of current production

(b) Proposed holistic NOx reduction, downsizing and heat recovery option

The rational for the case $2 \mathrm{~B}$ engine architecture is due to the requirement of examining holistic approaches in NOx reduction, downsizing and exhaust heat recovery. The current production of truck engines utilises relatively low rates of EGR. Furthermore, over a wide engine operating map, due to variable rates of EGR and boost pressure, the proportion of EGR and charge air heat are intermittent. As a result, firstly, to recover EGR and exhaust heat in parallel branched flow ORC, relatively low and precise flow rates of working fluid are required in the EGR HEX. This is also a challenge for the three-way flow distribution valve located at the pump exit. Secondly, EGR and charge air heat is available at two different quality levels, creating a further challenge in process integration. From the ORCs perspective, mixing and cooling both the charge air heat and the EGR heat in a common LT HEX may offer three potential advantages. Firstly, reduced number of thermal components, secondly, increased quantity of heat in the LT HEX, and finally, medium quality of heat which is suitable for series heat recovery prior to the exhaust heat. In the simulated case, the heat 
source temperature entering the combined $\mathrm{HEX}$ was $188^{\circ} \mathrm{C}$ as a result of mixing the charge air $\left(140^{\circ} \mathrm{C}\right)$ and the $\mathrm{EGR}$ stream $\left(500^{\circ} \mathrm{C}\right)$.

It can be noted that in option 2A (Table 3), which corresponds to series charge air and exhaust heat recovery, the exhaust HEX thermal duty was lowered by $14 \%$ for the same level of power output. Furthermore, option 2B, which corresponds to the series combined HEX and exhaust heat recovery, the exhaust HEX thermal duty was lowered by $34 \%$ for the same level of power output. The reduced exhaust HEX thermal duty for equal ORC net power in options $2 \mathrm{~A}$ and $2 \mathrm{~B}$ was since, the lower temperature exhaust heat recovery was replaced with heat sources that are already a load on the engine cooling module.

Finally, option 3 may be considered for exhaust heat recovery only, but in demanding condenser packaging applications, like the European trucks. In this option, the working fluid was slightly superheated compared to options 1 and 2 (from 215 to $250^{\circ} \mathrm{C}$ ). The level of superheating paired with the drying nature of the working fluid allowed the use of an Internal Heat Exchanger (IHE) to partially recover the exergy that may be lost in the condenser. Due to the internal heat recuperation, the exhaust heat recovery was reduced by $13 \%$, but more importantly, the condenser heat rejection was lowered by $15 \%$. Note that, the presented work has been limited to utilising a maximum of two HEXs during heat recovery. Although more complex arrangements are possible using the three HEXs, it's currently unclear if the added complexity offers any techno-economical benefits.

\section{Demonstration phase}

\subsection{ORC test-rig}

Following the two-part simulation study on working fluid (Fig. 3) and flexible thermal platform (Table 3), a range of parametric studies using pure water, water-alcohol blends and pure alcohols were conducted. The overall range of the simulation results were then translated into: system specification and layout, process and instrumentation diagram, and the procurement plan, which acted as the design reference for the experimental ORC test-rig. Due to the prototype nature of the work, control and instrumentation, hazard and operability, and risk assessment studies were undertaken. Noteworthy items included: temperature and pressure limits of gaskets and O-rings; burner emissions under different fuelling and backpressure conditions; independent mechanical 
pressure relief valve and pulsation damper; and forced alcohol vapour extractions from enclosed prototype components.

Figure 6 presents the complete test-rig representation at its current status. The test-rig is not aimed at demonstrating the power-density ratio of a commercial system, but is aimed at conducting working fluid research, demonstrating HT ORC operation, guiding development by evaluating components etc. The relatively large foot-print of the test-rig is due to the fact that the balance of the plant was sourced from the process industry to achieve the target variable thermal and pressure rating with high safety margins (e.g. test pressure of 84 bar in the case of the HT HEX).

Additionally, the test-rig is built with the aim to characterise components of varying capacities from different industrial sectors, alongside testing different thermal platforms.

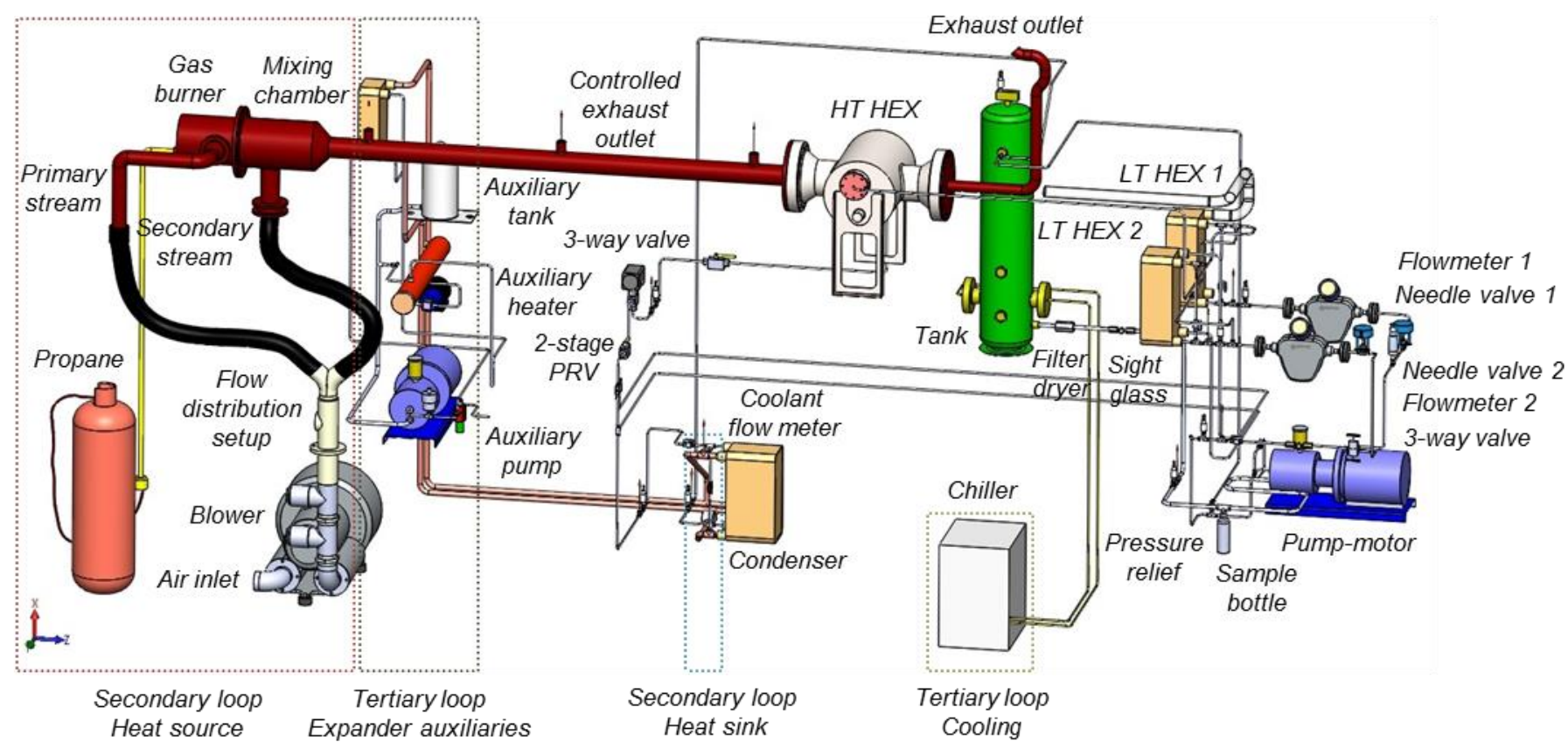

Figure 6 In-house experimental ORC test-rig with three HEXs in mixed series and parallel flow for

alcohols and water-alcohol blends utilised in the 'concept-to-demonstration' of the thermal

architecture phase of the work

As shown in Fig. 6, the test-rig comprises of five flow loops: ORC fluid, heat source, heat sink, chiller and auxiliaries. The key ORC fluid loop components, following the flow from the pump inlet include: HydraCell pump-motor; Johnson pressure relief valve; HydraCell pulsation damper, HiP 3-way valve; 
valve; Swagelok Pressure Reducing Valve (PRV); SWEP brazed plate condenser and Bitzer liquid receiver tank. In addition, the pump inlet includes, HVAC sight glass and Swagelok particulate filter and Swagelok sample cylinder. This sample line will be utilised in future works to quantify thermal degradation in pure alcohols and water-alcohol blends as a function of time, pressure and temperature exposures.

409 Considering the pump, the HT HEX, the PRV and the condenser forming the four temperature-pressure quadrants, Table 4 lists further component information, and additionally, summarises the section limits of the test-rig at its current status. The tank pressure limit paired 412 with the sight glass temperature limit provided the capability of up to 9 bar and $85^{\circ} \mathrm{C}$ at the LP LT section. Whereas, the HT HEX pressure and temperature limits provided the capability of up to

41440 bar and $380^{\circ} \mathrm{C}$ at the HT HP section.

Table 4 ORC fluid loop component information and section pressure-temperature capability limits

\begin{tabular}{ll}
\hline Component & Comment/Section limit \\
\hline ORC pipework & $\begin{array}{l}\Phi 10 \mathrm{~mm} \text { (branched parallel flow) } \\
\text { to } \Phi 18 \mathrm{~mm} \text { (full flow). Continuous } \\
\text { orbit welded, pressure tested with } \\
12 \text { bar (LP section) to } 45 \text { bar (HP } \\
\text { section) }\end{array}$ \\
& \\
LT HP section & - \\
HydraCell G10 diaphragm pump-motor & 48 bar \\
Johnson 1216HP pressure relief valve & $100^{\circ} \mathrm{C}$ \\
HydraCell RD pulsation damper & - \\
HiP 76NFC 3-way manual ball valve & - \\
Swagelok n-series air-actuated needle & \\
valve & \\
HT HP section & $225^{\circ} \mathrm{C}$ \\
SWEP V120T brazed plate HEX & 40 bar, $380^{\circ} \mathrm{C}$ \\
Vahterus 3HH welded plate and shell HEX & - \\
HiP 76NFC 3-way air-actuated ball valve & - \\
Swagelok KCY pressure reducing regulator & - \\
MT LP section & \\
SWEP B200 brazed plate condenser & - \\
Bitzer FS liquid receiver tank & 9 bar, $120^{\circ} \mathrm{C}$ \\
LT LP section & \\
HVAC JJ sight glass & 42 bar, $85^{\circ} \mathrm{C}$ \\
Swagelok SS particulate filter & - \\
Swagelok 304L sample cylinder & - \\
Aermec Venice20 water cooled chiller & - \\
\hline
\end{tabular}

419 The ORC loop pipework, which varied between 10-18 $\mathrm{mm}$ in diameter, was continuous orbit 420 welded. A brazed plate liquid cooled condenser was utilised due to its ability to withstand a wider 
421 range of condensation pressures and temperatures. As a result, condensing characteristics relevant

422 to both stationary and mobile ICE applications can be simulated. Furthermore, the tank was

423 modified to receive the chiller loop as a safety measure and as a means to draw down lower boiling

424 point fluids from the system.

\subsection{Preliminary experimental results and discussion}

427 Data was captured and logged using CompactRIO and five $\mathrm{Al}, \mathrm{AO}, \mathrm{MIO}$ modules. The Emerson

428 micro-motion Coriolis/density and Flowstat Pelton wheel flowmeters were used for the ORC fluid

429 and coolant loop, respectively. A total of 12 Omega K-type thermocouples and 7 Omega pressure

430 transducers were utilised to derive the thermodynamic conditions at key state points to create the

431 T-S diagram. Table 5 lists further instrumentation information, and additionally, summarises the

432 measurement accuracy and range.

434 Table 5 ORC test-rig instrumentation, accuracy and range

\begin{tabular}{|c|c|}
\hline Instrumentation & Comment \\
\hline $\begin{array}{l}\text { National Instruments } \\
\text { LabVIEW } 2014\end{array}$ & $\begin{array}{l}\text { CompactRIO (9074) at a logging rate of } 0.01 \mathrm{sec} \text {; } \\
\text { Al modules }(9201,9203,9237) \text {; AO module (9265); } \\
\text { MIO module (9381) }\end{array}$ \\
\hline $\begin{array}{l}\text { Emerson CMFS050M } \\
\text { micro-motion Coriolis flow } \\
\text { and density meter }\end{array}$ & Accuracy of $\pm 0.25 \%$ in the range of $0.018-1.8 \mathrm{~kg} / \mathrm{s}$ \\
\hline $\begin{array}{l}\text { Omega K-type (KMTXL) } \\
\text { thermocouples }\end{array}$ & 6 for working fluid; 4 for heat source; 2 for heat sink \\
\hline $\begin{array}{l}\text { Omega PX1009L0 and } \\
\text { PXM35MD pressure } \\
\text { transducers }\end{array}$ & $\begin{array}{l}7 \text { for working fluid; Accuracy } \pm 0.25 \% \text { (Max. } 149^{\circ} \mathrm{C} \text {, } \\
100 \text { bar); Accuracy } \pm 0.25 \% \text { (Max. } 343^{\circ} \mathrm{C}, 68.9 \\
\text { bar); Pre-calibrated and verified against Druck PV } \\
\text { multi-function pump }\end{array}$ \\
\hline $\begin{array}{l}\text { Flowstat CSD Pelton } \\
\text { wheel coolant flowmeter }\end{array}$ & Accuracy of $\pm 2 \%$ in the range of $0.25-2.5 \mathrm{~kg} / \mathrm{s}$ \\
\hline
\end{tabular}

437 Figure 7a-e presents key process parameters over a 1 minute duration from a steady-state test with 438 the thermal architecture configured as option 1 (Table 3). Steady-state was defined as a 3 minute 439 duration where the change in fluid at the HT HEX exit was limited below $2.5^{\circ} \mathrm{C}$ and 0.75 bar from a 440 set target value. The exhaust temperature at the inlet and exit of the HT HEX was 385.1 and $441248.7^{\circ} \mathrm{C}$ (Fig. 7a), while the water-glycol coolant temperature at the inlet and exit of the condenser 442 was 50 and $57.1^{\circ} \mathrm{C}$ (Fig. 7b). In the initial demonstrations presented here, deionised water (97\% by 443 mass) was used as the working fluid to demonstrate the high temperature and pressure operational 444 capability. The reason to utilise water was to facilitate commissioning and system development 
445 prior to introducing alcohols in the system. Note that, the test-rig is fully compatible with a wide 446 range of alcohols and their water blends.

447
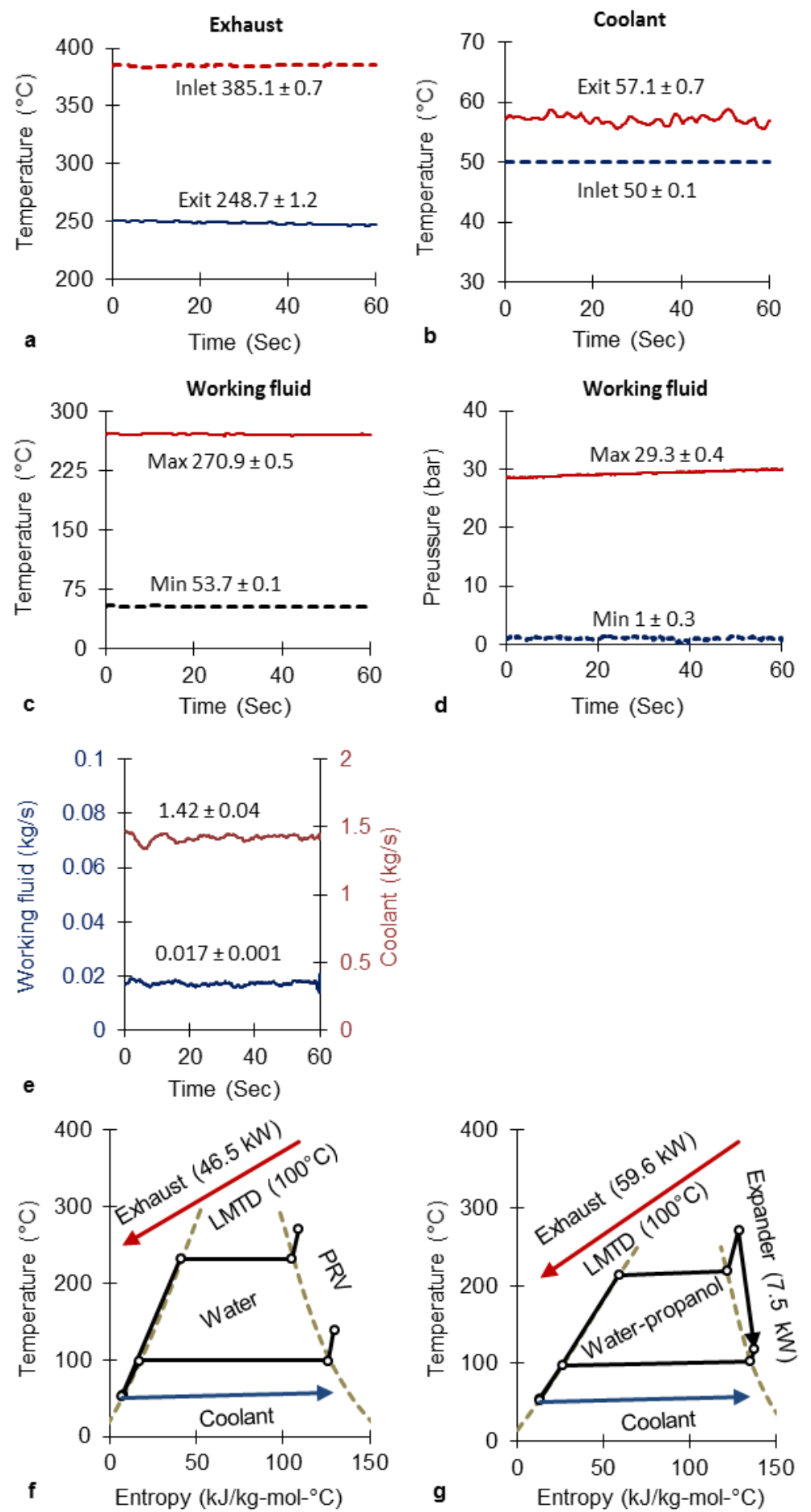

449 Figure 7 Off-design steady-state demonstration test results as option 1 arrangement (a) Source 450 quality (b) Sink quality (c) Fluid temperature limits (d) Fluid pressure limits (e) ORC fluid and coolant 451 flow rates ( $f$ ) T-S diagram of the process using a PRV $(g)$ Potential T-S diagram when utilising 452 water-propanol blend paired with a high-pressure ratio expansion process 
453 The HT HEX exit temperature $\left(270.9^{\circ} \mathrm{C}\right.$, Fig. 7c) and pressure (29.3 bar, Fig. 7d) was targeted to be 454 comparable to that required by the water-propanol blend in Fig. 3. To simulate the inlet and exit 455 pressures of the high-pressure ratio expander, which will be required under HT differential ORCs, a 456 PRV was utilised. Furthermore, the successful demonstration of throttling via the PRV is critical. This 457 is since, under start-up and transient conditions, which may correspond to two-phase at the HT HEX 458 exit, the flow needs to be by-passed when using conventional expanders and turbines. With a fluid 459 flow rate of $0.017 \mathrm{~kg} / \mathrm{s}$ (Fig. 7e), an average of $46.5 \mathrm{~kW}$ of heat was recovered in the HT HEX 460 (Fig. 7f). Compared to the thermal design point of the test-rig, the preliminary tests were simulated 461 at a relatively benign heat source condition, since the aim was to demonstrate stable operation. A 462 result of the off-design condition can be seen in Fig. 7f, where high level of working fluid reserve 463 was available in the tank, contributing to the high sub-cooling.

Figure 8a-e presents key process parameters from another 1 minute duration from a steady-state test, but with the thermal architecture being configured as option 2B (Table 3), i.e. combined cooler 467 heat recovery by the LT HEX. The exhaust temperature at the inlet of the HT HEX was $395.7^{\circ} \mathrm{C}$, 468 whereas, the temperature at the inlet and exit of the LT HEX was 190.5 and $112.8^{\circ} \mathrm{C}$ (Fig. 8a). These values were targeted to be comparable to the $188^{\circ} \mathrm{C}$ and $115^{\circ} \mathrm{C}$ simulation values from section 2.4.

470 The coolant inlet and exit temperature was 20.5 and $46.4{ }^{\circ} \mathrm{C}$ (Fig. 8b). The fluid maximum/minimum 471 temperature and pressure of $216.1 / 35.8^{\circ} \mathrm{C}, 19.9 / 0.9$ bar was achieved at a flow rate of $0.016 \mathrm{~kg} / \mathrm{s}$ 472 (Fig. 8c-e). The resulting T-S diagram of this process is presented in Fig. 8f. Note that, the parallel 473 branched flow (Fig. 6) is fully instrumented, hence a further option is possible in which both the LT 474 HEXs are utilised by controlling the flow via the 3-way valve at the pump exit. 

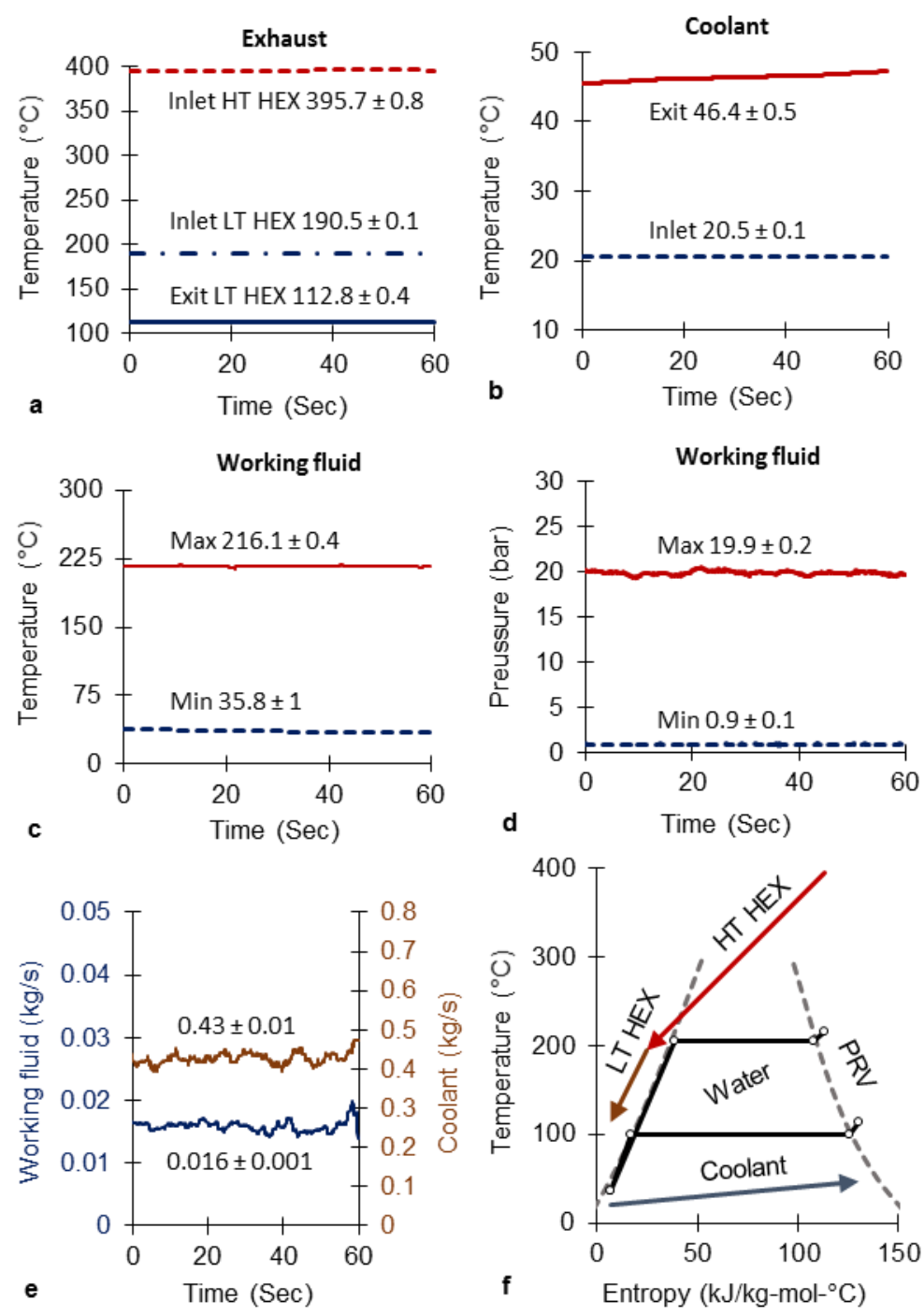

Figure 8 Off-design steady-state demonstration test results as option 2B arrangement (a) Source quality (b) Sink quality (c) Fluid temperature limits (d) Fluid pressure limits (e) ORC fluid and coolant flow rates (f) T-S diagram of the process using a PRV

\subsection{Power generation potential}

481 To estimate the recoverable power for the steady-state demonstration test condition, the 482 experimental measurements of option 1 were utilised in the ORC model. The PRV was replaced 483 with a $65 \%$ efficient two-stage expander with a pressure ratio of $4.6: 1$ each. Additionally, the working fluid was also replaced to the water-propanol blend. Figure $7 \mathrm{~g}$ shows the resulting T-S diagram of the ORC, which offered a potential expander power of $7.5 \mathrm{~kW}$ for $59.6 \mathrm{~kW}$ of heat recovery. The generated expander power using water-propanol blend was $12 \%$ higher when compared against pure water. This was since, assuming a similar LMTD value in the HT HEX, the blend recovered higher quantities of exhaust heat (59.6 vs. $46.5 \mathrm{~kW}$ ). This was principally due to the 
tailored, and rather reduced, latent heat of vaporisation of the water-propanol blend compared to pure water. This also supports in explaining why water has been suggested as a working fluid for heat source qualities above $500^{\circ} \mathrm{C}[1,5]$, and will in fact offer lower overall conversion efficiencies for typical exhaust heat recovery. Finally, assuming similar heat to expansion power conversion rate as that of Fig. $7 \mathrm{~g}$, the ORC test-rig can be tailored for efficient expansion machines up to $15 \mathrm{~kW}$.

The 'concept-to-demonstration' of the thermal architecture, as summarised in this paper, concludes the first phase of the activity. Figure $3 \mathrm{~d}$ and $7 \mathrm{~g}$ also highlight the next key phase of the activity, i.e. investigation of high overall expansion ratio machines. To this effort, it can be noted that the test-rig (Fig. 6) includes four expander auxiliary components (pump, heater, tank, HEX) which can be adapted for lubrication and cooling of expansion machines during development. With the added potential of tolerating two-phase expansion, the next key phase of the activity is expected on reciprocating expanders. The ability of an expansion machine to operate under high-pressure differentials and with varying fluid phases results in, increased average power in transient conditions and increased heat recovery in reduced heat quality conditions [17], boding the case for ORC in challenging applications.

\section{Conclusion}

A programme of 'concept-to-demonstration' is underway at the University of Brighton to investigate some of the challenges hindering the widespread adoption of ORCs. With a focus on, heat source setup, utilisation of exhaust gases, working fluid, process operating conditions and heat recovery platform, this paper has summarised the methodology and demonstration phase of activity relating to the thermal architecture. The current key features of the experimental ORC test-rig which may contribute towards investigating reduced system costs and increased overall conversion efficiency can be summarised as:

Variable heat source setup: Offering the potential of research and development for a wide capacity range of components under realistic ICE conditions. This is since, the blower-burner setup can be tailored for heat qualities and quantities between $200-500^{\circ} \mathrm{C}$ and $12-120 \mathrm{~kW}$, respectively. Direct exhaust heat utilisation: Projected to reduce the specific evaporator exergy cost by $22 \%$ when compared to a LT ORC coupled with a thermal-oil loop. Furthermore, the reduction in components and complexity, for equal net power, is vital in mobile applications. 
520 Water-alcohol blends: Estimated to increase the potential of overall conversion efficiency by 2.4

521 times when compared to a system utilising R245fa. This additionally guides the rationale for the 522 need of new ORC practice in HT applications.

523 Flexible thermal platform: Utilisation of two LT-HEXs in the parallel branch flow followed by the one 524 HT-HEX that can be configured for multiple and/or efficient heat utilisation for a variety of ICE 525 applications. Additionally, a holistic approach (by using combined HEX) to NOx reduction (by recovering EGR heat), downsizing (by recovering charge air heat) and exhaust heat recovery is proposed in the case of truck engines. The combined cooler and exhaust heat recovery can then reduce the additional heat rejected by the engine cooling module by $34 \%$ for an equal net power when compared to exhaust heat recovery only option.

Advanced process conditions: Demonstrated stable working fluid pressure (29.3 bar) and temperature $\left(270.9^{\circ} \mathrm{C}\right)$ capability corresponding to the near-optimal region identified by the simulation studies. When considering water-propanol blend, this offers the heat recovered to expansion power potential of $12.5 \%$.

534 The 'concept-to-demonstration' of the thermal architecture concludes the first phase of the activity. Investigations using reciprocating expanders operating under high-pressure differentials and with varying fluid phases will be the focus of future works.

\section{Acknowledgements}

The construction of the ORC test-rig presented in this paper was principally funded by the Innovate 540 UK (101566) and the University of Brighton's strategic investment. The contributions of Emily Pike-Wilson and Richard Sansome are noted.

\section{Reference}

544 1. Sprouse III, C. and C. Depcik, Review of organic Rankine cycles for internal combustion

2. Stanton, D.W., Systematic Development of Highly Efficient and Clean Engines to Meet 1395-1480. 
550 3. Nafey, A.S. and M.A. Sharaf, Combined solar organic Rankine cycle with reverse osmosis desalination process: Energy, exergy, and cost evaluations. Renewable Energy, 2010. 35(11): p. $2571-2580$.

4. Tchanche, B.F., et al., Low-grade heat conversion into power using organic Rankine cycles - A review of various applications. Renewable and Sustainable Energy Reviews, 2011. 15(8): p. 3963-3979.

5. Saidur, R., et al., Technologies to recover exhaust heat from internal combustion engines. Renewable and Sustainable Energy Reviews, 2012. 16(8): p. 5649-5659.

6. Weerasinghe, R., R. Stobart, and S. Hounsham, Thermal efficiency improvement in high output diesel engines a comparison of a Rankine cycle with turbo-compounding. Applied Thermal Engineering, 2010. 30(14-15): p. 2253-2256.

7. Wang, T., et al., A review of researches on thermal exhaust heat recovery with Rankine cycle. Renewable and Sustainable Energy Reviews, 2011. 15(6): p. 2862-2871.

8. Edwards, S., et al., Waste Heat Recovery: The Next Challenge for Commercial Vehicle Thermomanagement. SAE Int. J. Commer. Veh., 2012. 5(1): p. 395-406.

9. Yang, F., et al., Parametric optimization and performance analysis of ORC (organic Rankine cycle) for diesel engine waste heat recovery with a fin-and-tube evaporator. Energy, 2015. 91: p. 128-141.

10. Zhang, Y.-Q., et al., Development and experimental study on organic Rankine cycle system with single-screw expander for waste heat recovery from exhaust of diesel engine. Energy, 2014. 77: p. 499-508.

11. Seher, D., et al., Waste Heat Recovery for Commercial Vehicles with a Rankine Process, in 21st Aachen Colloquium Automobile and Engine Technology, October 8-12, Aachen, Germany. 2012.

12. Yang, M.-H. and R.-H. Yeh, Thermo-economic optimization of an organic Rankine cycle system for large marine diesel engine waste heat recovery. Energy, 2015. 82: p. 256-268.

13. Arunachalam, P.N., et al., Waste Heat Recovery from Multiple Heat Sources in a HD Truck Diesel Engine Using a Rankine Cycle - A Theoretical Evaluation. 2012, SAE International, 10.4271/2012-01-1602.

14. Wang, E.H., et al., Performance analysis of a novel system combining a dual loop organic Rankine cycle (ORC) with a gasoline engine. Energy, 2012. 43(1): p. 385-395. 
581 15. Yılmaz, A., Transcritical organic Rankine vapor compression refrigeration system for intercity bus air-conditioning using engine exhaust heat. Energy, 2015. 82: p. 1047-1056.

16. Shu, G., et al., Parametric and exergetic analysis of waste heat recovery system based on thermoelectric generator and organic rankine cycle utilizing R123. Energy, 2012. 45(1): p. 806-816.

17. Panesar, A., Waste Heat Recovery Using Fluid Bottoming Cycles For Heavy Duty Diesel Engines. 2015, PhD. thesis. School of Computing, Engineering and Mathematics, University of Brighton, DOI: 10.13140/RG.2.1.4559.0248.

18. Morgan, R., et al., A comparative study between a Rankine cycle and a novel intra-cycle based waste heat recovery concepts applied to an internal combustion engine. Applied Energy, 2016. 174: p. 108-117.

19. Aspen Technology Software, HYSYS version 8. 2015.

20. National Instruments, LabVIEW. 2014.

21. Shu, G.Q., et al., Simulations of a Bottoming Organic Rankine Cycle (ORC) Driven by Waste Heat in a Diesel Engine (DE). 2013, SAE International, 10.4271/2013-01-0851.

22. Guillen, D., et al. Development of a Direct Evaporator for the Organic Rankine Cycle. in TMS Annual Meeting, February 27 - March 3, San Diego, USA. 2011.

23. Lakew, A.A. and O. Bolland, Working fluids for low-temperature heat source. Applied Thermal Engineering, 2010. 30(10): p. 1262-1268.

24. Tchanche, B.F., et al., Fluid selection for a low-temperature solar organic Rankine cycle. Applied Thermal Engineering, 2009. 29(11-12): p. 2468-2476.

25. Karellas, S., A. Schuster, and A.-D. Leontaritis, Influence of supercritical ORC parameters on plate heat exchanger design. Applied Thermal Engineering, 2012. 33-34(0): p. 70-76.

26. Li, W., et al., Effects of evaporating temperature and internal heat exchanger on organic Rankine cycle. Applied Thermal Engineering, 2011. 31(17-18): p. 4014-4023.

27. Braimakis, K., et al., Low grade waste heat recovery with subcritical and supercritical Organic Rankine Cycle based on natural refrigerants and their binary mixtures. Energy, 2015. 88: p. 80-92.

28. Shu, G., et al., Alkanes as working fluids for high-temperature exhaust heat recovery of diesel engine using organic Rankine cycle. Applied Energy, 2014. 119: p. 204-217.

29. Ricardo Software, WAVE version 8.1. 2015. 